\title{
A protocol for a systematic map of review studies on the potential environmental impacts of shale gas development
}

\author{
S. A. Clancy ${ }^{1}$; R. Brown ${ }^{1 *}$; G. Stewart ${ }^{1}$; R.S. Ward ${ }^{2}$; R. Davies ${ }^{1}$ \\ 1. School of Natural and Environmental Sciences, Newcastle University, UK \\ 2. Groundwater Science Directorate, British Geological Survey, Keyworth, Nottingham NG12 5GG, UK \\ *Corresponding author. E-mail address: rachel.brown@newcastle.ac.uk.
}

\begin{abstract}
With the possible development of a shale gas industry within the UK, many review studies have been written in an attempt to further understand and identify potential environmental impacts related to shale gas extraction. However, until now, these review studies have not been critically assessed to determine their rigor. This article outlines the protocol for a systematic map of review studies on the potential environmental impacts of shale gas extraction by hydraulic fracturing. The main aim of this study is to systematically map peer-reviewed and non-peer-reviewed review studies and assess the abundance and quality of the evidence. Secondary objectives will also be explored in relation to assessing the distribution of the literature available on different environmental impacts, including impacts to water, land and air. The results of this systematic map will be used to inform recommendations for further research.

This protocol outlines the reasoning, objectives, inclusion and exclusion criteria, search strategy and the screening processes for the systematic map. This report includes details on the plans for data extraction and data synthesis.
\end{abstract}

Keywords: Shale gas, Hydraulic fracturing, Environmental impact, UK, Systematic map.

\section{Protocol}

\subsection{Background}

Shale gas exploitation in the UK is in its early stages, at the time of writing three shale gas wells in the UK, located in Lancashire (Preese Hall and two wells at Preston New Road (PNR-1Z and PNR-2)) have been hydraulically fractured since 2011. With the potential for further shale gas wells to be drilled within the UK and a possibility of a shale gas industry being developed, considerable investment has been made to undertake independent research to understand the potential environmental impacts on shale gas development within a UK setting. The Natural Environment Research Council (NERC) and Economic \& Social Research Council (ESRC) have funded the Unconventional Hydrocarbons in the UK Energy System (UKUH) Programme. This systematic map protocol of review studies on the potential environmental impacts of shale gas development has been performed as part of the UKUH Programme in order to document:

- the quality and abundance of review studies on this topic;

- the distribution of the literature available on different environmental impact receptors, including water, land and air; and

- gaps within the literature. 
In the US, production of shale gas has increased from around 7.6 billion cubic metres $(\mathrm{bcm})$ in 1990 (Tyndall Centre, 2011 cited U.S. Energy Information Administration, 2010) to about $477.4 \mathrm{bcm}$ in 2017 (U.S. Energy Information Administration, 2018). Since large-scale production of shale gas began in the US, and with the possibility of a shale gas industry being developed within the UK, several controversies surrounding the potential environmental impacts and risks have arisen within the literature (Cooper et al., 2014; Prpich et al., 2016). Within this study, environmental impact is defined as the impact on the environment created by a shale gas industry'. The term risk areas are defined as 'the likely areas that are impacted by harmful consequences as a result of shale gas developments'. Environmental impacts and risk areas highlighted by the literature include: air pollution; water contamination/abstraction; soil contamination; noise; light pollution; visual impact; traffic; changes in land use; and climate change (Cooper et al., 2016; Goodman et al., 2016; Cotton et al., 2014).

In recent years, the body of scientific literature evaluating risk areas related to shale gas developments has grown considerably, although data gaps remain (Hays et al., 2015). These publications have subsequently been collated into review studies to allow for a wider understanding of the board range of potential environmental impacts (examples include: The Royal Society and The Royal Academy of Engineering, 2012; Scottish Government, 2014; California Council on Science and Technology, 2015; United States Environmental Protection Agency, 2015). Despite an increasing number of review studies being published within this field, the quality and breath of these reviews has not yet been assessed.

\section{Why is it important to do this study?}

Considering the potential development of a shale gas industry within the UK, it is timely to understand and identify what has been already been learnt with regards to potential environmental impacts and risk areas. The UK could learn valuable lessons from the numerous review studies carried out throughout the world, especially those from the US, where there is a longer history of shale gas development. Despite this, to our knowledge, there is no (non-health specific) systematic map or meta-analysis of review studies on the potential environmental impacts and/or risk areas of shale gas extraction by hydraulic fracturing, which follow the guidelines for the formation of a high-quality systematic map; based on Collaboration for Environmental Evidence standards (CEE). The approach taken for this systematic map involves identifying any existing review studies and critically appraising the quality of the review studies. The resulting systematic map will be used to identify key research areas that have been covered within the assessed review studies. It will also allow for knowledge gaps to be identified, to aid in addressing where future research efforts should be concentrated.

This systematic map protocol will provide extensive overview of the methodology for the systematic map.

\subsection{Objectives}

As outlined in Section 1.1 there is a need to identify and critically assess the reviews currently published on the potential environmental impacts and risk areas associated with shale gas extraction by hydraulic fracturing. The key objectives of the review are as follows:

- Assess the strength of evidence and quality of the review studies by answering the following questions:

0 is there a methods section on how the review was performed?;

o did the review have an inclusion and/or exclusion criteria?;

o did the review consider publication bias?;

0 is the review systematic?;

0 is the review repeatable?; and 
o how many references did the study use?

- Determine the location the review was carried out in and the location the literature used within the review was based. This information will be mapped to assess where the majority of data used within the studies is from and where the different reviews are being produced, this will assist in producing a picture of how environmental concerns related to hydraulic fracturing potentially change within different regions across the global.

- Provide an overview of the distribution and abundance of literature in relation to the potential environmental impacts and risk areas, including impacts to water, land and air. These impact themes will likely be further classified during the systematic mapping process when the volume of publications is known.

- Assess where there are literature and data gaps within the key environmental impact themes and risk areas.

\section{Criteria for considering studies for the review}

\subsection{Types of studies to be included}

This systematic map is focused on appraising review studies on the potential environmental impacts of shale gas extraction by hydraulic fracturing. Both peer-reviewed and grey literature will be included in this study. Grey literature may include: government reports, technical/regulatory guidance, scenariobased studies, environmental impact statements, policy briefs, white papers and law review articles. Conference abstracts will be excluded from this study.

\subsection{Types of outcome measured}

The outcomes measured will relate to the primary objects of the systematic map.

The strength of the evidence and quality of the review will be classified based on the following points: (1) presence of a methodology; (2) presence of an inclusion/exclusion criteria; (3) consideration of publication bias; (4) if the review was systematic; (5) repeatability of the review; (6) number of references used. Details of where the review was carried out and the location the literature used within the review was based will be recorded. Whether the review included literature on environmental impacts related to air, land or water will be recorded. Literature and data gaps within the key environmental impact themes and risk areas will also be assessed. These outcomes will be presented in a table and a map format.

\section{Search strategy for identification of studies}

\subsection{Search strategy}

Reviews will be acquired using Scopus, CAB Abstracts, Compendex, ProQuest Natural Science Collection and Web of Science. Within ProQuest the following search databases used are: AGRICOLA, TOXLINE, MEDLINE, ASFA, MGA and ESPM. To reduce publication bias Google Scholar, the IHS Environmental Database and Westlaw UK will also be searched as a source of grey literature. To further reduce publication bias, key authors in the field will be consulted to check for any unpublished literature, and secondly reference lists will be screened to confirm that all relevant reviews have been captured from the database searches.

Table 1. Electronic databases used for searching 


\begin{tabular}{ll}
\hline Database & Search field \\
\hline Scopus & Title, abstract and keywords \\
CAB Abstracts & All text \\
Compendex (Engineering Village) & Subject, title and abstract \\
ProQuest Natural Science Collection & NOFT \\
Web of Science & Topic \\
Google Scholar & Title
\end{tabular}

Only reviews published between January 2009 and January 2019 will be included in this study, this will allow for 10 years of review studies to be assessed. This 10 -year period covers: time prior to the first shale gas well being hydraulically fractured in the UK; when the first well was hydraulic fracturing in the UK; when there was a moratorium on hydraulic fracturing within the UK; and when the moratorium was lifted and hydraulic fracturing was permitted again and further wells were drilled. In addition, to be included in the systematic map, publication must be available in English.

Key search terms have been developed to identify literature that possibly contains information relevant to the assessment of environmental impacts related to shale gas development. Search terms will be built upon combinations of primary, secondary and tertiary search terms (Table 2). Boolean operators will be used to connect and define the relationships between the different search terms. The three Boolean operators that will be used are AND, OR and NOT. Subject headings, titles, keywords and abstracts will be screened for the search terms. Search terms will be refined after several test searches to ensure the most appropriate search terms are being used. Search terms will be checked using key authors and reviews.

Table 2: Keywords considered for search

\begin{tabular}{cc}
\hline Primary & $\begin{array}{c}\text { "fracking"OR"shale gas"OR"natural gas"OR"hydraulic } \\
\text { fractur*"OR"unconventional gas"OR"frakking"OR"unconventional } \\
\text { shale gas"OR"fraccing" }\end{array}$ \\
\hline AND & "review"OR"meta analysis" \\
\hline Secondary & NOT \\
\hline Tertiary & "health" \\
\hline
\end{tabular}

\subsection{Search screening}

All of the literature that is retrieved using the search terms in Table 2 will be imported to Endnote and recorded in folders based on where the literature was acquired from and according to its type of publication (peer-reviewed or grey literature). Once all the literature has been collected, duplications will be removed and analysis of eligibility for the review will be performed.

Within this study, a review is defined as document that is all of the following: 
- based on secondary research;

- does not include primary data;

- includes more than one independent study; and

- is not an evidence briefing.

The literature imported to Endnote will screened for eligibility as below:

1. Title, abstracts and keywords search: Initially the primary researcher will screen the publication's title, abstract and keywords to ensure the publication is an environmental review associated with hydraulic fracturing. A second reviewer will then review at least $10 \%$ of these studies. Where a consensus is not present, any differences will be resolved through discussion. If there are any outstanding uncertainties, the study will be included within the second screening. Where the publication is not deemed to be a review it will not be considered further.

The publications that pass this eligibility screening process will undergo a 180 degree review. This method requires the references of the eligible publication to also be reviewed. Once these publications have been acquired, they will be screened in the same manner as the initial abstracted publications.

\section{Method of review}

\subsection{Data management and extraction}

The required data will be extracted from the included studies by the primary researcher using a data extraction form in Microsoft Excel (Table 3). The data extraction form will be finalised as the nature of the data becomes apparent. To assess if the data extraction form is suitable it will be tested by two independent researchers on five key studies to check all relevant information is extracted. The final review paper will contain a copy of the final data extraction form. 
Table 3: Initial data extraction form.

\begin{tabular}{|c|c|c|c|c|c|c|c|c|c|c|c|c|c|c|c|c|c|c|c|}
\hline $\begin{array}{c}\text { UKUH } \\
\text { Reference }\end{array}$ & $\begin{array}{c}\text { Date } \\
\text { reviewed }\end{array}$ & Author & Title & $\begin{array}{c}\text { Year } \\
\text { Published }\end{array}$ & $\begin{array}{l}\text { Study type } \\
\text { (peer- } \\
\text { review/grey } \\
\text { literature) }\end{array}$ & $\begin{array}{c}\text { Journal } \\
\text { name }\end{array}$ & $\begin{array}{c}\text { Data } \\
\text { source } \\
\text { location }\end{array}$ & $\begin{array}{l}\text { Study } \\
\text { location }\end{array}$ & Air & $\begin{array}{l}\text { hich are } \\
\text { focus }\end{array}$ & the study & $\begin{array}{l}\text { Number of } \\
\text { citations }\end{array}$ & $\begin{array}{l}\text { Number of } \\
\text { references }\end{array}$ & $\begin{array}{l}\text { Was the } \\
\text { review } \\
\text { systematic? } \\
\text { (yes/no) }\end{array}$ & $\begin{array}{l}\text { Methods } \\
\text { section } \\
\text { present } \\
\text { (yes/no) }\end{array}$ & $\begin{array}{l}\text { Is the review } \\
\text { repeatable? } \\
\text { (yes/no) }\end{array}$ & $\begin{array}{c}\text { Inclusion } \\
\text { and/or } \\
\text { exclusion } \\
\text { criteria } \\
\text { present } \\
\text { (yes/no) }\end{array}$ & $\begin{array}{c}\text { Publication } \\
\text { bias } \\
\text { considered } \\
\text { (yes/no) }\end{array}$ & $\begin{array}{l}\text { Protocol } \\
\text { present? } \\
\text { (yes } / \mathrm{no})\end{array}$ \\
\hline
\end{tabular}




\subsection{Data mapping}

The studies that make it through the screening process will be included within the systematic map. These studies will be spilt into the impact areas (air, water, land - Table 4) they cover. Where studies fall into more than one research area, it will be recorded. From this analysis, the research within the review papers will be evaluated to identify any data gaps. This will allow informed discussions to be determined on where further research should potentially be carried out within the UKUH Programme.

Table 4: Summary of key search terms as adapted by Pripich et al., 2016.

\begin{tabular}{ll}
\hline Impact areas & Key search terms \\
\hline Water & Water quality; water use; water treatment; waste water; water \\
& contamination; water storage \\
Air & $\begin{array}{l}\text { Air quality, fugitive emissions; flaring methane; greenhouse gases; global } \\
\text { warming }\end{array}$ \\
Land & $\begin{array}{l}\text { Subsurface; seismicity; land contamination; biodiversity; ecology, traffic; } \\
\text { well integrity, noise, light, soil contamination }\end{array}$ \\
\hline
\end{tabular}

\subsection{Display data}

The data collected during this review will be displayed in the final report in the following formats:

- a flow diagram (e.g. Figure 1): highlighting the number of studies identified, reviewed, included and excluded;

- review of the literature: 'Data extraction table' - see Table 3; and

- map of overall findings. 
Figure 1: An example of the flow diagram that will be generated (based the PRISMA 2009 flow diagram, PRIMSA, 2019).
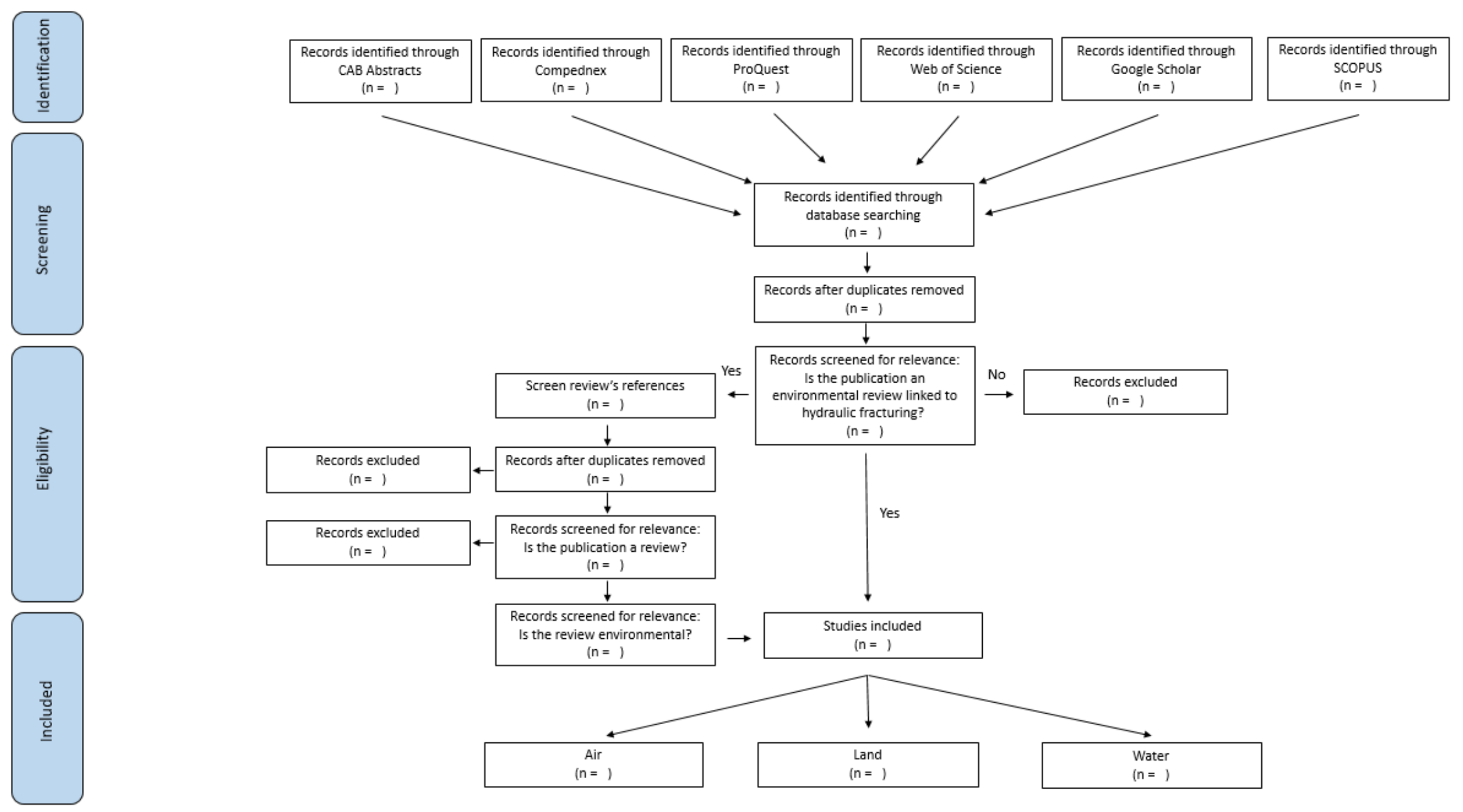


\section{References:}

California Council on Science and Technology, 2015. An independent scientific assessment of well stimulation in California, Volume II: Potential environmental impacts of hydraulic fracturing and acid stimulations. https://escholarship.org/uc/item/6mp4080p (cited 13 February 2019).

Cooper, J., Stamford, L., Azapagic, A., 2014. Environmental impacts of shale gas in the UK: current situation and future scenarios. Energy Technology 2(12): 1012-1026.

Cooper, J., Stamford, L., Azapagic, A., 2016. Shale gas: A review of the economic, environmental, and social sustainability. Energy Technology 4(7): 772-792.

Costa, D., Jesus, J., Branco, D., Danko, A., Fiúza, A., 2017. Extensive review of shale gas environmental impacts from scientific literature (2015-2010). Environmental Science Pollution Research 24: 1457914594.

Cotton, M., Rattle, I., Alstine, J. V., 2014. Shale gas policy in the United Kingdom: An argumentative discourse analysis. Energy Policy 73: 427-438.

Cuadrilla, 2018. Cuadrilla granted hydraulic fracturing consent for second horizontal shale gas well. https://cuadrillaresources.com/media-resources/press-releases/cuadrilla-granted-hydraulic-fracturingconsent-for-second-horizontal-shale-gas-well/ (cited 12 February 2019).

Cuadrilla, 2018. Hydraulic fracturing to go ahead at shale gas exploration site in Lancashire. https://cuadrillaresources.com/media-resources/press-releases/hydraulic-fracturing-to-go-ahead-atshale-gas-exploration-site-in-lancashire/ (cited 12 February, 2019).

U.S. Energy Information Administration, 2018. Frequently asked questions: how much shale gas is produced in the United States? (https://www.eia.gov/tools/faqs/faq.php?id=907\&t=8) cited 13 February 2019).

Goodman, P. S., Galatioto, F., Thorpe, N., Namdeo, A. K., Davies, R. J., Bird, R. N., 2016. Investigating the traffic-related environmental impacts of hydraulic-fracturing (fracking) operations. Environmental International 89-90: 248-260.

Hays, J., Finkel, M. L., Depledge, M., Law, A., Shonkoff, S. B. C., 2015. Science of the Total Environment 512-513: 36-42

MSKTC (Model Systems Knowledge Translation Centre). No date. A guide for developing a protocol for conducting literature reviews. http://ph.cochrane.org/sites/ph.cochrane.org/files/public/uploads/Guide\%20for\%20PH\%20protocol_N ov\%202011_final\%20fo r\%20website.pdf (cited 12 December 2018).

Peters, M., Mcinerney, P., Godfrey, C., Baldini Soares, C., 2015. Methodology for JBI scoping reviews. The Joanna Briggs Institute Reviewers' Manual 2015. file:///C:/Users/nsc268/Downloads/ReviewersManual Methodology-for-JBI-Scoping-Reviews 2015 v2.pdf (cited 12 December 2018). 
PRISMA $2009 \quad$ Flow Diagram. http://www.prismastatement.org/documents/PRISMA\%202009\%20flow\%20diagram.pdf (cited 13 February 2019)

Prpich, G., Coulon, F., Anthony, E. J., 2016. Review of the scientific evidence to support environmental risk assessment of shale gas developments in the UK. Science of the Total Environment 563-564: 731740.

Scottish Government, 2014. Independent expert scientific panel - Report on unconventional oil and gas. https://www.gov.scot/binaries/content/documents/govscot/publications/report/2014/07/expertscientific-panel-report-unconventional-oil-gas/documents/00456579-pdf/00456579pdf/govscot\%3Adocument (cited 13 February 2019).

The Royal Society and The Royal Academy of Engineering, 2012. Shale gas extraction in the UK: A review of hydraulic fracturing. https://www.raeng.org.uk/publications/reports/shale-gas-extraction-in-the-uk (cited 13 February 2019).

Tyndall Centre, University of Manchester on behalf of The Co-operative, 2011. Shale Gas: An Updated Assessment of Environmental and Climate Change Impacts.

United States Environmental Protection Agency, 2015. Assessment of the potential impacts of hydraulic fracturing for oil and gas on drinking-water resources (external review draft). U.S. Environmental Protection Agency, Washington, DC, EPA/600/R-15/047, 2015. file:///C:/Users/nsc268/Downloads/HF ERD JUN2015\%20(1).PDF (cited 13 February 2019). 


\title{
6. Supplementary information
}

\subsection{Plans for updating the protocol}

Feedback on the protocol from the stakeholder advisory group will be taken into consideration post protocol registration and submission. This is to increase transparency and minimise the potential for bias.

The data extraction form will be confirmed after critical appraisal; the final form will be included within the final document.

\section{About the systematic map}

The systematic map will be produced by the Working Group and reviewed by a Review Panel and the UKUH Programme Advisory Board, further details on the member of these groups can be found below.

\author{
7.1 Anticipated contributions of authors \\ Sarah Clancy - SC \\ Rachel Brown - RB \\ Gavin Stewart - GS \\ Rob Ward - RW \\ Richard Davies - RD \\ Protocol development: SC, RB, RW, GS \\ Run search: SC \\ Identification of relevant titles and abstracts: SC \\ Identification of relevant studies: SC \\ Obtain relevant studies: SC \\ Data extraction: $\mathrm{SC}, \mathrm{RB}$ \\ Quality appraisal: SC, RB \\ Data analysis and interpretation: SC, RB, GS, RW \\ Draft systematic map: SC, RB, GS, RW \\ Review systematic map: SC, RB, GS, RW, RD \\ Final report for systematic map: SC, RB, GS, RW, RD
}

\subsection{Team}

\section{Working Group}

The following Working Group was set up to oversee this project. Members of the Working Group developed the research questions and the systematic map's methodology. Members of the Working Group acted in an individual and not a representative capacity and declared and potential conflicts of interest (Section 7.3).

- Dr Sarah Clancy. Sarah is a Research Associate on the UKSGL project and is based at Newcastle University. She is an environmental geoscientist and her research focuses on the potential environmental risks of shale gas extraction by hydraulic fracturing. 
- Rachel Brown. Rachel is the Project Manager for UKSGL Project and is based at Newcastle University. She is a hydrogeologist by background has been working as Project Manager for the ReFINE research consortium since 2017.

- Dr Gavin Stewart. Gavin is a Senior Lecturer in Evidence Synthesis at Newcastle University.

- Dr Rob Ward. Rob is the Director of Science at the BGS in Keyworth. He is a hydrogeologist working in both groundwater science and environmental regulation.

- Professor Richard Davies. Richard is the Pro-Vice Chancellor of Engagement and internationalization at Newcastle University. He is a petroleum geologist who specialises in the movement of geological fluids through rocks and since 2011 the environmental impacts of fracking.

\section{Review Panel}

An independent panel of experts from the British Geological Survey (BGS) and the UKUH Programme will review this report. Members of the panel will not endorse the report's conclusions. Prior to carrying out any review work, the panel will declare any potential conflicts of interest.

\section{Stakeholder Advisory Group}

The Stakeholder Advisory Group will be made up of members of the UKUH Programme Advisory Board (PAB). The members of the PAB board comprise of representatives from policy makers, regulators, operators, environmental non-government organisations and professional organisations.

\subsection{Sources of support}

The research councils NERC and ESRC have funded this review through the Unconventional Hydrocarbons in the UK Energy System: Environmental and socio-economic impacts and processes Programme (UKUH). The aims of this research Programme are to provide an updated independent scientific evidence base to understand potential environmental and socio-economic impacts of unconventional hydrocarbon development.

\subsection{Preliminary timeframe}

Protocol development: December 2018 - September 2019

Database searching: September 2019

Data sifting: September 2019

Data extraction: October 2019

Quality appraisal: October - November 2019

Data analysis: November 2019

Key conclusions: December 2019 